\title{
Special issue in honor of Professor Bjørn Gjevik
}

\author{
John Grue
}

Received: 8 June 2010 / Accepted: 6 July 2010 / Published online: 25 July 2010

(C) The Author(s) 2010. This article is published with open access at Springerlink.com

Keywords Ocean processes $\cdot$ Small scale $\cdot$ Meso scale $\cdot$ Ocean modeling $\cdot$ Nonlinear surface and internal waves $\cdot$ Turbidity currents and submarine slides

\section{Symposium and Bjørn Gjevik's scientific work}

The papers of this special issue discuss small- and meso-scale processes in the ocean and their modeling. They were presented at, or in conjunction to, a symposium, entitled, 'Topics in geophysical fluid dynamics and renewable energy in the offshore environment', in celebration of the Norwegian hydrodynamicist and geophysicist, Professor Bjørn Gjevik, on the occasion of his 70th birthday. More than 90 participants attended the Symposium, which was hosted by the Norwegian Academy of Science and Letters in Oslo, on 16 October 2009. One of the sessions was devoted to offshore wind power. The papers from this part of the symposium will be published elsewhere.

Bjørn Gjevik, working at the University of Oslo (UiO), Norway, is mostly known for his early works on the stability of thin films (Gjevik 1970). Entirely on his own, he introduced the equation $\eta_{t}=Q_{x}, Q=$ $Q(\eta)$ for the film elevation $\eta$, combining the effects of gravity, viscosity, nonlinearity and capillarity. Gjevik's inclusion of the surface tension could, for the first time, predict and explain the stability of supercritical thin

Responsible Editor: Jörg-Olaf Wolff

\section{J. Grue $(\bowtie)$}

Mechanics Division, Department of Mathematics,

University of Oslo, Oslo, Norway

e-mail: johng@math.uio.no film motion. His theoretical predictions agreed very well with experiments, performed under house arrest, by later Nobel Laureate Pyotr Leonidovich Kapitsa (Kapitsa 1948), which by that time were not explained theoretically. Bjørn Gjevik's papers were defended for the Dr. Philos. degree at UiO in 1972, with Mårten Landahl (KTH), Eivind Riis and Enok Palm in the committee (image).

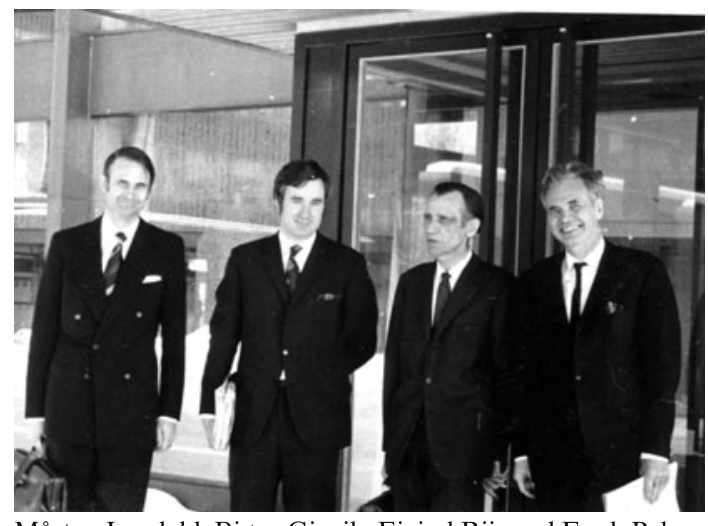

Mårten Landahl, Bjørn Gjevik, Eivind Riis and Enok Palm

The equation Bjørn Gjevik derived includes soliton solutions with friction and surface tension. Alekseenko et al. (1994, p. 99) credit Gjevik (1970) as the first to develop the equation $h_{t}+3 h^{2} h_{x}+3 \epsilon\left(\frac{12}{5} h^{5} \mathrm{Re}-\right.$ $\left.\cot \theta h^{2}\right) h_{x}^{2}+\epsilon\left(\frac{6}{5} \operatorname{Re} h^{6}-\cot \theta h^{3}\right) h_{x x}+3 W \epsilon^{3} h^{2} h_{x} h_{x x x}+$ $W \epsilon^{3} h^{3} h_{x x x x}=0, h=1+\eta$ film thickness, $\theta$ slope angle, $W$ dimensionless surface tension, $\epsilon$ dimensionless amplitude, Re Reynolds number. Recent threedimensional film waves studies, e.g. Scheid et al. (2006) credit Gjevik (1970) for deriving $h_{t}+\frac{1}{3}\left\{h^{3}+\right.$ $\left.\frac{2}{35} \delta\left(h^{7}\right)_{x}-\frac{1}{4} \zeta\left(h^{4}\right)_{x}+h^{3} h_{x x x}\right\}_{x}=0, \delta$ reduced Reynolds number, $\zeta$ the effect of gravity along the normal of 
the sloping plane, but term it the Benney equation, being a variant of the work by Benney (1966), showing that the velocity may be represented by a polynomial series in the normal coordinate, with coefficients being functions of the film thickness, leaving out, however, the essential effect of surface tension. Other works quote the equation as being of the Benney-Gjevik type (Alekseenko et al. 1995); it took more than 30 years before an improved one-equation reduction of the Orr-Sommerfeld equation was developed (Panga and Balakotaiah 2003), illustrating Bjørn Gjevik's vital and groundbreaking contribution to thin film and colloid research. Bjørn Gjevik's personal success was also a triumph for his scientific environment and illustrates the strength and impact of Norwegian hydrodynamics, stability theory and nonlinear mechanics in the 1960s and 1970s, where a small group at UiO was highly vital. Bjørn Gjevik tells, particularly, about his fascination of the considerable drive, enthusiasm and focus on fundamental problems by Enok Palm, Professor of Applied Mathematics at UiO.

In 1971, he was hired as Senior Lecturer in Solid Earth Physics at the Department of Geophysics at UiO and started working on elastic waves: P-, S-, Rayleighand Love waves. Thanks to the new oil activity in Norway, work on seismic prospecting became a Klondike! He also began working on visco-plastic models for upheaval (Gjevik 1972). Such models are commonly used in studies of how the crust slowly relaxes after ice loading. Bjørn Gjevik published three works based on phase transitions between the different terrestrial crystal structures. The pressure at the surface drives the phase transitions and causes a volume change and subsequent adjustment of the crust. Heat conduction and latent heat determine the reaction time in the phase transitions which then determines the relaxation time. The time scale of the upheaval appears by using information from typical phase transitions in the Earth's interior. The model gives good predictions for subsidence in sediment basins formed at the outlet of big rivers.

In 1972-1973, Bjørn Gjevik was a post-doc with Professor John W. Miles at Scripps Institution of Oceanography in La Jolla, San Diego. Arriving in California, John Miles asked: "What do you want to work with?" "Variational principles for elastic waves", he replied. At Scripps, there were several seismologists and one day John Miles came, saying: "A physicist-geologist David Griggs from UCLA, with expertise in geodynamics, wants to speak with you. He has published ground breaking experiments with viscous fluids and continental drift (Holmes 1965, p. 1036) and is reading your papers." It appeared that David Griggs, at the age of 80 years, had gone in detail through the work by Gjevik (1972), re-deriving the formulas.

In 1977, Bjørn Gjevik was appointed as Professor of Hydrodynamics at the Department of Mathematics at UiO. Many students were attracted by his lectures. All among his 65 graduate students praise him as their favorite teacher, lecturing always with a charming smile! He was Department Chair from 1981 to 1983. Administrative duties then and later were always carried out in an excellent way. Bjørn Gjevik became an Elected Member of the Norwegian Academy of Science and Letters in 1981.

Bjørn Gjevik was the first to calculate the storm surge along the Norwegien coast (jointly with Lars Petter Røed, see Gjevik and Røed 1976). Particularly much cited are his works (one jointly with Tom Marthinsen) on lee waves in the atmosphere at Jan Mayen (Gill 1982). Likewise, a joint work with Geir Pedersen provides a breaking criterion for the runup and run-down, referred to as the Gjevik-Pedersen criterion (Chen and Scawthorn 2002). In two larger EU-projects, Genesis and Impact of Tsunamis along European Coasts (GITEC) I and II, from 1993 to 1999, Gjevik and Pedersen collaborated with expert groups in Italy, France, Spain and Portugal. The EU-project Fluxes Across Narrow Shelves (FANS), 1996-1999, under MAST-III, focused on vortex formation and instability of currents on the shelves of Spain. Later, vortex formation in the Norwegian-Atlantic Current (the Gulf Stream) was studied with a similar method. Bjørn Gjevik has participated in the Geohazards Centre of Excellence at the Norwegian Geotechnical Institute (NGI) and several publications came out of these projects.

Bjørn Gjevik was the first to calculate the tide and effect of wind stress in the Norwegian Sea, Greenland Sea, Barents Sea and the Polar Ocean, coupling the motion between the basins. Predictions compared well to available measurements (Davies 1990). Calculating the current-induced, Lagrangian particle drift in the ocean, he applied the theory to estimate the drift of ice bergs, fish larvae and pollution (Grue et al. 1996). In a dissertation for the Doctor's degree, one of his students, Atle Ommundsen, calculated how cod larvae that are hatched in Vestfjorden, may drift through the Sounds of Lofoten, northward along the Norwegian coast, before reaching the Barents Sea, where the fry mature.

The Norwegian offshore industry has frequently requested predictions of wave and current conditions. The vulnerability of safety pipelines, marine operations and platform installations led Hydro, Saga Petroleum and Statoil to request a survey of wave and current 
conditions on the continental shelf. During the construction of the pipeline from the platforms Heidrun and Draupner to the refinery on Tjeldbergodden, Statoil and Shell requested Bjørn Gjevik to work out detailed current maps on the Halten bank and along the Norwegian coast, from Stad to Vikna. Later, Statoil requested a Tidal Atlas for the shelves along the Norwegian coast, Barents Sea and Svalbard (Gjevik et al. 1994). Recently, the Norwegian Deep Water Program, supported by eight oil companies, requested a review of the current conditions on the continental shelf slope, both in shallow and deep water and, in particular, the formation of vortices that are formed in the shear currents along the shelf edge.

Together with younger colleagues, Bjørn Gjevik wrote an article on Nature, on fine-scale predictions of the tide in Lofoten and Vesterålen, explaining the mystic Maelstrom at Lofotodden (Gjevik et al. 1997). Complementary reports were published in the New York Times and in a popular French magazine, Science $\&$ Vie. Together with young collaborators, he continues the work on fine scale predictions of the tide in the coastal area and fjords. A recent effort is directed to Electronic Cart Display Systems, where the purpose is to enhance safety of transport in resticted waters. More important, however, is the fundamental research dimension, where the fine scale predictions contribute to resolving the energy cascades in the ocean. Through reversed cascades, local motion may contribute to the global ocean circulation, a topic at the forefront of current international oceanography (Ferrari and Wunsch 2009).

Bjørn Gjevik recently wrote a popular text on the tides, storm surges, flood waves, landslides, natural hazards, upheaval and climate change. Throughout the 351 pages he nicely describes and illustrates his scientific life project (Gjevik 2009).

\section{Childhood and youth}

Bjørn Nilsen Gjevik was born on the 30th of March in 1939. Conditions in the coastal environment formed his childhood. Together with two brothers, he grew up in the village of Tranvikan in Fillan county on Hitra island, Norway, in the 1940s and 1950s. His father, Bjarne Nilsen, was a skipper on various ships in the ocean-going fishing fleet, and sailed the banks along the coast, in the Barents Sea and around Iceland. At an age of more than 90 years, the father told, for the first time, about an experience on the Halten bank, 50 years earlier: a monster wave in the form of a huge wall of water rose ahead of his 50-60 ft long ship, a moment he believed he and his colleagues would not survive. His mother, Nikoline, was a housewife who was active in the Society for Sea Rescue and the Congregation. She had a dedicated interest in animals and vegetation and all that was moving in nature. The social environment on Hitra had a considerable outlook to the bigger world. Stories were told by those working in ocean fishing and the trade fleet working the Norwegian coast, the Norwegian Sea, to Greenland, Iceland and the Barents Sea.

The school was divided in two. The teachers had basic student exam qualifications and practiced in the school before proceeding to higher studies. Bjørn Gjevik tells from the age of 11-12 years about one of the teachers, Sunniva Thiis. She was outstanding and fitted in smoothly and well with the people in the small village. She put the students to work with lots of mathematical excercises and workbooks. Among several innovations, the school adopted a ship in the trade fleet and, cutting and glueing news, the students made newspapers and wrote letters to the crew. MT Julian, a tanker sailing to Venezuela, in the Caribbean and the Persian Gulf, made a particularly strong impression. The captain made practical exercises which the students had to solve: For example, if the ship tanks were filled with a certain volume of oil, how much would it expand if the sea temperature rose to another level? The captain corrected the exercises by the students. The practical tasks were highly stimulating and the engagement was great. In the interest of practising English, Sunniva Thiis offered free lessons to young Bjørn, who, on his side, was keen to learn about the bigger world.

On his way to higher studies-he chose mathematics and physics at UiO from 1959 onwards-he attended Orkdal Senior High School (1954-1958). Summer holidays were spent as deck hand in line fishing on the Halten bank. When he received the Cand. Real. degree (M.Sc.) in mechanics in 1965, he was already hired as Research Assistant for Professor Einar Høiland, the dominant presence in the hydrodynamic environment in Oslo for a generation. In 1963, Bjørn Gjevik married Anne-Lise Kojedal. They have two children, Elen and Jonas, and three grandchildren.

\section{The papers of this Special Issue}

The first of the eight papers of this Special Issue, following the Editorial, is co-authored by Birgit Kjoss Lynge, Jarle Berntsen and Bjørn Gjevik and discusses particle dispersion in Moskstraumen. It is directly related to Gjevik et al.'s (1997) paper in Nature on the 
Maelstrom, and his works on drift and dispersion of particles (Grue et al. 1996). By means of a Smagorinsky model with constant coefficient, the small-scale eddies are resolved in grids down to a finest horizontal resolution in the range between 800 and $50 \mathrm{~m}$. Computations of the small-scale effect on the particle dispersion show convergence for the two finest resolutions. The effect of stratification in Moskstraumen is shown to be small.

The same theme-effect of the small-scale processes upon the larger scale-is undertaken in the numerical investigation by John E. Jones, Alan M. Davies and Jiuxing Xing. They use a graded finite element model of the Irish Sea and the Mersey estuary to compute how small-scale topographic features influence the barotropic surge and tidal dispersion. Model of baroclinic sill flow, allowing for short nonlinear internal waves at the lee side, contribute to enhanced mixing and affect the global motion.

Jon Albretsen and Lars Petter Røed run two different ocean model systems-MIPOM and ROMSto hind-cast the circulation pattern in the North Sea/Skagerak area. Testing eddy-permitting $(4 \mathrm{~km})$ and eddy-resolving $(1.5 \mathrm{~km})$ grids, they conclude that the area consists of randomly distributed mesoscale structures, which are crucial to resolve, at least statistically. The current prediction with MIPOM below the mixed layer is found to improve with increasing resolution, reflecting the effect of the bottom topograpy. Surface currents become more accurate with ROMS than MIPOM.

Calculations supplement ocean currents measurements, where the latter are obtained by drifters in various variants and cover a large part of the world oceans. Inga Kozalka and Joseph H. Lacasce present a new, alternative method for how current velocity and eddy diffusivity can be obtained from sets of drifters. Rather than using geographical bins, they group the drifters by nearest-neighbor distance using a clustering algoritm. This has the advantage that the number of observations is the same for each cluster, providing a more uniform statistical accuracy.

While all among the first four papers relate to the core of Bjørn Gjevik's work on predictions of currents, particle drift and dispersion, the next three papers are in direct relation to his work on wave phenomena. Motivated by interpretation of data from ocean wave measurements, Harald E. Krogstad and Karsten Trulsen discuss linear and nonlinear stochastic theory of ocean waves. Starting out with a Gaussian linear model, they derive a perturbation expansion to third order in the average wave steepness. This produces the usual nonlinear cubic correction of Stokes waves, but also reveals second order contributions to the spectrum away from the first order dispersion magnifold. By simulations they illustrate how the nonlinear evolution of unidirectional free waves does not follow the linear dispersion surface.

John Grue and J. Kristian Sveen propose a scaling law of internal run-up duration. An internal wave of long initial elevation, propagating in a two-fluid system with constant density in the layers, with a thin upper layer, interacts with a weak slope. The velocity and duration of the onshore flow of dense water at the undisturbed pycnocline slope-intersection is investigated by a set of laboratory measurements and compared with an observation of a strong bottom current event recorded on the Ormen Lange gas field. The event is driven by the thermocline motion at the location. An internal solitary wave of depression interacting with the slope, disintegrates into a train of shorter waves and form a set of boluses.

Internal solitary waves is the subject also of the paper by Magda Carr, Marek Stastna and Peter A. Davies. The waves of depression or elevation interact with small-scale bathymetric variability, induce flow separation and lee vortices, where the latter develop fully after the main wave has passed by the bottom corrugation, resulting in deformation of the overlying pycnocline and possible enhanced vertical mixing. The bottom features enhance spatio-temporal shear instability, and wave-bottom induced billows may extend vertically by up to the half of the wave amplitude.

The flow of submarine landslides is the subject of the final paper by Anders Elverhøi et al., and relates in part to Bjørn Gjevik's work on tsunamis generated by slides or seismics, and the subsequent run-up, where Bjørn Gjevik particularly studied the waves due to the Loen, Tafjord and Storegga slides (Gjevik et al. 1997b; Harbitz et al. 1993). The paper discusses submarine landslides that show extraordinary mobility. While some slides show compact features for hundreds of kilometers, other disintegrate during the flow and eventually develop turbidity currents. How turbitidy currents versus submarine landslides contribute in reshaping the continental margins is discussed. The Storegga land slide, Bear Island Fan and the 1929 Grand Banks slide are studied in particular.

Open Access This article is distributed under the terms of the Creative Commons Attribution Noncommercial License which permits any noncommercial use, distribution, and reproduction in any medium, provided the original author(s) and source are credited. 


\section{References}

Alekseenko SV, Nakoryakov VE, Pokusaev BG (1994) Wave flow of liquid films. Begell House, Redding, CT

Alekseenko SV, Nakoryakov VE, Pokusaev BG (1995) Int J Multiph Flow 11:607-627

Benney DJ (1966) J Math Phys 45:150-155

Chen W-F, Scawthorn C (2002) Earthquake engineering handbook. CRC Press, Boca Raton, FL

Davies AM (1990) Modeling marine systems, vol I. CRC Press, Boca Raton, FL

Ferrari R, Wunsch C (2009) Annu Rev Fluid Mech 41:253282

Gill AE (1982) Atmosphere-Ocean dynamics. Academic, New York

Gjevik B (1970) Phys Fluids 13:1918-1925

Gjevik B (1972) Phys Earth Planet Inter 5:403-408
Gjevik B (2009) Flo og fjære langs kysten av Norge og Svalbard (In Norwegian) Farleia Forlag, $351 \mathrm{pp}$

Gjevik B, Røed LP (1976) Tellus 28(2):166-182

Gjevik B, Nøst E, Straume T (1994) J Geophys Res 99(C2):33373350

Gjevik B, Moe H, Ommundsen A (1997) Nature 388, 837-838, (28 August 1997)

Gjevik B et al (1997b) J Geophys Res 103(C13):27931-27949

Grue J, Gjevik B, Weber JE (1996) Waves and nonlinear processes in hydrodyamics. Kluwer, Norwell, MA

Harbitz CB, Pedersen G, Gjevik BJ (1993) Hydraul Eng 19(12):1325-1342

Holmes A (1965) Principles of physical geology, 2nd edn. The Ronald Press Company, New York

Kapitsa PL (1948) Zh Eksper Teor Fiz 18:3-28

Panga MK, Balakotaiah V (2003) Phys Rev Lett 90:154501

Scheid B, Ruyer-Quil C, Manneville P (2006) J Fluid Mech 562:183-222 